\title{
Arterial stiffness can occur early in mild-to- moderate chronic obstructive pulmonary disease
}

\author{
Waleed Mansour ${ }^{1}$, Mohamed El-Shabrawy ${ }^{1}$, Wael A. Khalil', Ahmad S. Eldamanhory ${ }^{2}$ and Sameh Embarak ${ }^{1 *}$ (D)
}

\begin{abstract}
Background: Chronic obstructive pulmonary disease (COPD) is a well-known respiratory system disorder impacting patient's morbidity and mortality. Many COPD patients die from cardiovascular diseases. Criteria of arterial stiffness might be the early clue for cardiovascular affection in COPD patients. This study aimed to evaluate the occurrence of arterial stiffness as an early subclinical change in stable mild to moderate COPD patients.

Results: This cross-sectional study included 80 mild-to-moderate COPD patients and another 80 healthy controls. The carotid-femoral pulse wave velocity (Cf-PWV) and the heart rate adjusted augmentation index (Alx75) were statistically significantly higher (13.8 \pm 2.6 and $23.9 \pm 10.8$, respectively) among studied mild-to-moderate COPD patients when compared to healthy controls (10.7 \pm 1.1 and $18.1 \pm 8.9$, respectively) $(p<0.001)$. FEV1 (forced expiratory volume in $1 \mathrm{~s}$ ) $\%$ of predicted correlated negatively with both Alx75 ( $r=-0.84, p<0.001)$ and cf-PWW $(r=-0.85, p<0.001)$, while BODE (body mass index, airflow obstruction, dyspnea, and exercise capacity) index correlated positively with both Alx75 $(r=0.58, p<0.001)$ and cf-PWV $(r=0.52, p<0.001)$ in patients with mild-to-moderate COPD.
\end{abstract}

Conclusions: Pulse wave velocity and augmentation index correlated with FEV1\% of predicted and BODE index in patients with mild-to-moderate COPD.

Keywords: Arterial stiffness, COPD, Pulse wave velocity, Augmentation index, BODE index

\section{Background}

Although chronic obstructive pulmonary disease (COPD) is a lung disorder, it is now well known to have systemic effects that significantly affect other systems and are poorly investigated regarding their impact on the ability to prognosticate morbidity and mortality [1]. Hypoxemia and systemic inflammation may be the cause and are independent of smoking [2, 3]. Multiple systems are implicated; however, the cardiovascular system is particularly affected independently of smoking history [4].

Many indices were used to predict the risk of death in COPD, e.g., BODE index, but neglected that many

\footnotetext{
* Correspondence: sembarak75@yahoo.com

'Pulmonary Medicine Department, Zagazig Faculty of Medicine, Zagazig,

Egypt

Full list of author information is available at the end of the article
}

COPD patients died from cardiovascular causes rather than of respiratory causes, and arterial stiffness could independently predict that risk [5] and might start early in COPD [2].

Comorbidity can affect COPD patients, however, is poorly investigated although it is significant impact on the prognosis of those patients. Cardiovascular changes are the most common and important; however early changes cannot be routinely assessed and searched for to be controlled with subsequent improvement of morbidity, mortality, and accordingly the prognosis of COPD $[3,4]$. So, the aim of this study was to evaluate the occurrence of arterial stiffness as an important subclinical cardiovascular change that might start early in stable mild-to-moderate COPD patients using a simple noninvasive tool. 


\section{Methods}

\section{Study design and setting}

This cross-sectional study was carried out at Chest and Cardiology Departments and Outpatient Clinics, Zagazig University Hospitals during the period from August 2017 through March 2019.

\section{Subjects}

The current study included eighty healthy control subjects, plus eighty stable mild-to-moderate (GOLD 1 or 2) COPD patients diagnosed and classified in accordance with the Global Initiative for Chronic Obstructive Lung Disease (GOLD) guidelines evidenced by spirometric airflow limitation (forced expiratory volume in $1 \mathrm{~s}$ [FEV1]/ forced vital capacity $[\mathrm{FVC}]<0.70)$ during clinical stability; plus post bronchodilator FEV1 $\geq 50 \%$ predicted ( mild $=$ GOLD1; FEV1 $\geq 80 \%$, moderate $=$ GOLD2; 50\% $\leq$ FEV1 < 80 [6]. Patients with a recent exacerbation (within 6 weeks), hyperlipidemia, hypertension, diabetes mellitus, ischemic heart disease, cerebrovascular accidents, collagen vascular disorders, hepatic diseases, and renal impairment were excluded.

The Ethics Committee of Zagazig Faculty of Medicine approved the current study. An informed written consent was collected from each participant.

\section{Methods}

The followings were done for all participants:

1- Full medical history taking and clinical examination with baseline data collection, e.g., age, sex, and body mass index $\left(\mathrm{kg} / \mathrm{m}^{2}\right)$.

2- Chest radiology (plain chest $\mathrm{x}$-ray and chest CT when needed) to exclude other diseases and complications.

3- Routine laboratory investigations including measurement of total lipid profile: serum total cholesterol (mg/dL), LDL cholesterol (mg/dLl), and HDL cholesterol (mg/dL).

4- ECG and Echocardiography.

5- Spirometry (Spirotube PC Spirometer, Thor Laboratories, Budapest, Hungary): $\mathrm{FEV}_{1}, \mathrm{FVC}$, and $\mathrm{FEV}_{1} / \mathrm{FVC}$ were measured.

6- Assessment of dyspnea using the modified Medical Research Council (mMRC) dyspnea scale with a score ranging from zero to four (zero: if dyspnea only with strenuous exercise, one: if dyspnea when hurrying or walking up a slight hill, two: if walks slower than people of the same age because of dyspnea or has to stop for breath when walking at own pace, three: if stops for breath after walking 100 yards $(91 \mathrm{~m})$ or after a few minutes, four: if too dyspneic to leave house or breathless when dressing [7].
7- Assessment of 6 min walk distance in meters (6MWD) [8].

8- Measurement of arterial blood gases (ABGs).

9- Assessment of BODE (body mass index, airflow obstruction, dyspnea and exercise capacity) index with a range from zero to ten [9].

10-Measurement of pulse wave velocity: the carotidfemoral pulse wave velocity (cf-PWV), central blood pressure, and augmentation index were measured after 30 min of complete physical and mental rest in supine position using a mobil-o-graph PWV monitor (IEM, Stolberg, Germany) using single oscillometric measurement of the brachial BP by simultaneously obtaining the pulse wave contour. The diastolic blood pressure level was maintained for $10 \mathrm{~s}$ in order to assess the pulse wave form [10]. The aortic pressure waveform was generated from the obtained brachial artery pulse waveform. Augmentation index was corrected for a heart rate of 75 beats/min (AIx75) which was automatically calculated by the PWV software [11]. Additional files $1,2,3$ and 4

\section{Statistical analysis}

Statistical analysis was performed with Epi Info ${ }^{\mathrm{TM}}$ version 7 and the SPSS version 19 statistical software package (SPSS Inc., Chicago, IL, USA). Continuous variables are expressed as mean and SD. Student's $t$ test was used to compare between normally distributed variables. Categorical variables are expressed as frequencies and percent. Differences in proportions were compared using the chi-squared or Fisher exact test. Non-normally distributed variable is expressed as median and range, and differences between groups were assessed using Kruskal-Wallis and/or Mann-Whitney tests. The correlation between parameters was calculated using Spearman's correlation. $p$ value $<0.05$ was considered significant.

\section{Results}

The current study included 80 patients with mild-tomoderate stable COPD (GOLD 1 or 2) with a mean age of $59.1 \pm 6.9$ years old. They were $73(91.25 \%)$ males and 7 (8.75\%) females. Another 80 healthy subjects were included as a control group with a mean age of $61.7 \pm 6.3$ years old. They were $71(88.75 \%)$ males and 9 (11.25\%) females. Different spirometric parameters including FVC $\%$ of predicted $(p=0.04)$, FEV1\% of predicted $(p<$ $0.001)$, and FEV1/FVC $(p<0.001)$ were significantly lower among studied COPD patients when compared to healthy controls. Also, there was a highly significant statistical difference between both studied groups as regard to the mMRC dyspnea scale, 6MWD, and BODE index $(p<0.001)$. Characteristics of all studied population are shown in Table 1. 
Table 2 shows hemodynamic parameters of all studied participants. COPD patients experienced higher systolic (either peripheral, $134 \pm 24 \mathrm{mmHg}$ or central, $126 \pm 14$ $\mathrm{mmHg}$ ) and diastolic (either peripheral, $84 \pm 7.9 \mathrm{mmHg}$ or central, $85 \pm 2.1 \mathrm{mmHg}$ ) blood pressures when compared to healthy controls (systolic peripheral, $119 \pm 17$ $\mathrm{mmHg}$ or central, $108 \pm 7 \mathrm{mmHg}$ and diastolic peripheral, $72 \pm 6.7 \mathrm{mmHg}$ or central, $74 \pm 1.2 \mathrm{mmHg}$, respectively) $(p<0.001)$. Also, cf-PWV and AIx75 were statistically significantly higher $(13.8 \pm 2.6$ and $23.9 \pm$ 10.8, respectively) among studied mild-to-moderate COPD patients when compared to healthy controls (10.7 \pm 1.1 and $18.1 \pm 8.9$, respectively) $(p<0.001)$.

Table 3 shows that FEV1\% of predicted correlated negatively with both AIx75 $(r=-0.84, p<0.001)$ and cf-PWV $(r=-0.85, p<0.001)$ in patients with mild-tomoderate COPD (GOLD 1 or 2)

Table 4 illustrates that BODE index correlated positively with both $\operatorname{AIx75}(r=0.58, \mathrm{p}<0.001)$ and cf-PWV $(r=0.52, p<0.001)$ in patients with mild-to-moderate COPD (GOLD 1 or 2$)$

\section{Discussion}

Cardiovascular events were found to be the second most common etiology of mortality following bronchogenic carcinoma in COPD patients [12]. The early affection of the cardiovascular system is important to solve the mystery of such a disease, which is now documented to have a wide range of systemic impact on the whole body. The arterial stiffness is especially important as it affects all parts of the body not only the cardiovascular one; however, the exact mechanism of its occurrence in COPD patients is still not exactly known and may be attributed to hypoxemia and connective tissue degradation resulting in arterial wall thickening, vascular remodeling, and formation of atherosclerotic plaque, which may start early in COPD $[2,4]$.

The population of the current study (GOLD 1 or 2 COPD and healthy controls) were matched regarding the parameters included in Table 1. Age is an important factor that can affect arterial stiffness; so in our study, we chose matched age population; however, AIx was not related to age [13].The smoking history of the studied population either current or ex-smokers showed no significant statistical difference which is in accordance with Mills et al. [4] and Zureik et al. [14]. On the other hand, Mahmud et al. [15] and Rehill et al. [16] documented the difference between smokers and nonsmokers regarding PWV, as well as chronic effects of smoking on AIx.

Regarding the BMI in our study, there was nonsignificant difference between both studied groups, which is in contrary to the study carried out by Mills et al. [4] who found a lower BMI in COPD patients than

Table 1 Characteristics of all studied participants

\begin{tabular}{|c|c|c|c|}
\hline Variables & COPD (GOLD 1 or 2$)(n=80)$ & Healthy controls $(n=80)$ & $P$ value \\
\hline Age, years & $59.1 \pm 6.9$ & $61.7 \pm 6.3$ & 0.18 \\
\hline Sex & & & 0.79 \\
\hline Male & $73(91.25 \%)$ & $71(88.75 \%)$ & \\
\hline Female & 7 (8.75\%) & $9(11.25 \%)$ & \\
\hline Smoking & & & 1.00 \\
\hline Current & $6(7.5 \%)$ & $5(6.25 \%)$ & \\
\hline Ex-smoker & $74(92.5 \%)$ & 75 (93.75\%) & \\
\hline Body mass index, $\mathrm{kg} / \mathrm{m}^{2}$ & $23.7 \pm 3.6$ & $24.6 \pm 4.2$ & 0.15 \\
\hline Serum total cholesterol, mg/dL & $187.4 \pm 36.5$ & $179.2 \pm 31.9$ & 0.13 \\
\hline LDL cholesterol, mg/dL & $121.9 \pm 36.8$ & $112.5 \pm 29.9$ & 0.08 \\
\hline HDL cholesterol, mg/dL & $49.9 \pm 13.1$ & $48.0 \pm 12.2$ & 0.34 \\
\hline Triglycerides, mg/dL & $129.4 \pm 27.1$ & $127.8 \pm 37.6$ & 0.76 \\
\hline FVC $\%$ of predicted & $83.3 \pm 12.4$ & $86.9 \pm 9.6$ & $0.04^{*}$ \\
\hline $\mathrm{FEV}_{1} \%$ of predicted & $69.6 \pm 15.8$ & $84.5 \pm 9.9$ & $<0.001^{* *}$ \\
\hline $\mathrm{FEV}_{1} / \mathrm{FVC}$ & $65.7 \pm 3.12$ & $78.6 \pm 6.76$ & $<0.001^{* *}$ \\
\hline mMRC dyspnea scale & $1(1-3)$ & $0(0-1)$ & $<0.001^{* *}$ \\
\hline 6 min walk distance, $\mathrm{m}$ & $425 \pm 60$ & $530 \pm 80$ & $<0.001^{* *}$ \\
\hline BODE index & $2(0-5)$ & $0(0-1)$ & $<0.001^{* *}$ \\
\hline
\end{tabular}

Values are presented as mean $\pm S D$, median (range), or number (\%) unless otherwise specified. COPD chronic obstructive pulmonary disease, GOLD 1 or 2 mild or moderate COPD, $H D L$ high-density lipoprotein, $L D L$ low-density lipoprotein, $B O D E$; body mass index, aiflow obstruction, dyspnea, and exercise capacity, FEV1 forced expiratory volume in $1 \mathrm{~s}$, FVC forced vital capacity, mMRC Modified Medical Research Council

*Significant, **highly significant 
Table 2 Hemodynamic parameters of all studied participants

\begin{tabular}{llll}
\hline Variables & COPD (GOLD1 or 2) $(n=80)$ & Healthy controls $(n=80)$ & $P$ value \\
\hline Heart rate (beats per min) & $69 \pm 8.9$ & $67 \pm 7.1$ & 0.12 \\
Peripheral systolic blood pressure $(\mathrm{mmHg})$ & $134 \pm 24$ & $119 \pm 17$ & $<0.001^{* *}$ \\
Peripheral diastolic blood pressure $(\mathrm{mmHg})$ & $84 \pm 7.9$ & $72 \pm 6.7$ & $<0.001^{* *}$ \\
Central systolic blood pressure $(\mathrm{mmHg})$ & $126 \pm 14$ & $108 \pm 7$ & $<0.001^{* *}$ \\
Central diastolic blood pressure $(\mathrm{mmHg})$ & $85 \pm 2.1$ & $74 \pm 1.2$ & $<0.001^{* *}$ \\
Cf-PWV $(\mathrm{m} / \mathrm{s})$ & $13.8 \pm 2.6$ & $10.7 \pm 1.1$ & $<0.001^{* *}$ \\
Alx75 & $23.9 \pm 10.8$ & $18.1 \pm 8.9$ & $<0.001^{* *}$
\end{tabular}

Values are presented as mean \pm SD unless otherwise specified. COPD chronic obstructive pulmonary disease, GOLD1 or 2 mild or moderate COPD, cf-PWV carotidfemoral pulse wave velocity, $A / x 75$ augmentation index normalized to a standard heart rate of 75 beats per min

**Highly significant

healthy controls. This could attribute to the difference in patient selection between our study and that of Mills et al. [4] as they included patients with more severe disease, while this work included only mild-to-moderate COPD patients.

COPD is associated with cardiovascular changes, which have an impact on prognosis [17], and we tried to prove it in the early stages of COPD disease (GOLD 1 or 2 ), where we found a significant difference regarding systolic blood pressure, diastolic blood pressure, pulse wave velocity, and AIx75 values between mil-to-moderate COPD patients and healthy controls coping with other studies like that of Mills et al. [4], McAllister et al. [5], Sabit et al. [13], and Maclay et al. [18] who found that PWV was higher in severe and very severe patients with COPD than in those with mild-to-moderate disease.

Zieman et al. [19] explained these changes by a "remodeling process" with collagen and elastin replacement in the extracellular matrix, which is induced by the systemic inflammation as well as "vascular calcification". In the study of Schulz et al. [20], the role of "neutrophil elastase activity" is also participating in the pathogenesis of such a change by consuming the elastic fibers in the media of the large arteries. According to Mills et al. [4], these mechanisms are attributed to the COPD per se and not due to the presence of comorbidity.

The current study found that FEV1\% of predicted correlated negatively with both AIx75 and cf-PWV in

Table 3 Correlation between FEV $1 \%$ of predicted, Alx75, and cf-PW in studied COPD patients

\begin{tabular}{|c|c|c|}
\hline & \multicolumn{2}{|c|}{$\mathrm{FEV}_{1} \%$ of predicted } \\
\hline & $r$ & $P$ value \\
\hline Alx75 & -0.84 & $<0.001^{* *}$ \\
\hline cf-PWV (m/s) & -0.85 & $<0.001^{* *}$ \\
\hline
\end{tabular}

COPD chronic obstructive pulmonary disease, FEV1 forced expiratory volume in $1 \mathrm{~s}$, cf-PWV carotid-femoral pulse wave velocity, Alx75 augmentation index normalized to a standard heart rate of 75 beats per min, $r$ Pearson's correlation coefficient test

**Highly significant patients with mild to moderate which was proven in other studies like that of Sabit et al. [13] and Zureik et al. [14]. In contrary, it was weaker in the study of McAllister et al. [5].

The prognosis of patients with COPD is not all attributed to the respiratory system alone and should be extended to include other systems notably the cardiovascular one, and this was declared frankly by Divo et al. [17]. They have a direct impact on the prognosis particularly through the excess cardiovascular morbidity and mortality because of increased arterial stiffness in those COPD patients [3].

The prognostic indices of COPD, e.g., BODE index, which ignored the importance of these changes in cardiovascular indices, should be extended [21]. We thought that arterial stiffness indices are of great importance and neglected by the pulmonologists. Hence, in the current study, we tried to throw some light on the significant positive correlation between the BODE index in mild-to-moderate COPD patients and both AIx75 and PWV. Sabit et al. [13] declared that arterial stiffness is a marker as well as a cause of cardiovascular diseases through affecting pulse pressure leading to increase after load of left ventricular and oxygen demand of myocardium with subsequent reduction of coronary perfusion leading to ischemia and subendocardial plaque formation, promoting vascular remodeling and arterial wall thickness [22, 23].

Table 4 Correlation between BODE index, Alx75 and cf-PWV in studied COPD patients

\begin{tabular}{lll}
\hline & BODE Index & \\
\cline { 2 - 3 } & $r$ & $P$ value \\
\hline Alx75 & 0.58 & $<0.001^{* *}$ \\
$\operatorname{Cf-PWV~}(\mathrm{m} / \mathrm{s})$ & 0.52 & $<0.001^{* *}$ \\
\hline COPD chronic obstructive pulmonary disease, BODE body mass index, airflow
\end{tabular}

COPD chronic obstructive pulmonary disease, $B O D E$ body mass index, aiflow obstruction, dyspnea, and exercise capacity, cf-PWV carotid-femoral pulse wave velocity, $A / x 75$ augmentation index normalized to a standard heart rate of 75 beats per min, $r$ Pearson's correlation coefficient test

**Highly significant 
Furthermore, a recent prospective study was performed on 76 patients with COPD. The researchers assessed the arterial stiffness of the included patients by annual measurement of the AIx over a period of 7 years and concluded a significant increase in arterial stiffness in their patients' overtime. Moreover, the amount of annual increase in AIx was correlated to the severity of emphysema [12]. On the other hand, pulmonary rehabilitation was found to have a possible role in modification of elevated aortic stiffness in a subgroup of COPD patients [24].

This work has some limitations. First, the sample size is considered low, second, other arterial stiffness confounders, e.g., accelerated local inflammation and impaired microcirculation, could not be addressed, and third, the cross-sectional design of the study. However, we tried to increase its power by adding a control group.

Finally, we recommend that cardiovascular changes should be targeted early in COPD patients in order to reduce its morbidity and improve prognosis of those patients.

\section{Conclusions}

Pulse wave velocity and augmentation index correlated with FEV1\% of predicted and BODE index in patients with mild-to-moderate COPD.

\section{Supplementary information}

Supplementary information accompanies this paper at https://doi.org/10. 1186/s43168-020-00014-1.

\section{Additional file 1 \\ Additional file 2. \\ Additional file 3. \\ Additional file 4}

\section{Abbreviations}

COPD: Chronic obstructive pulmonary disease; cf-PWV: Carotid-femoral pulse wave velocity; Alx75: Augmentation index normalized to a standard heart rate of 75 beats per min; GOLD: Global Initiative for Chronic Obstructive Lung Disease; LDL: Low-density lipoprotein; HDL: High-density lipoprotein; BODE: Body mass index, airflow obstruction, dyspnea, and exercise capacity; FEV1: Forced expiratory volume in $1 \mathrm{~s}$; FVC: Forced vital capacity; mMRC: Modified Medical Research Council; BMI: Body mass index; 6MWD: 6min walk distance; $\mathrm{ABG}_{\mathrm{s}}$ : Arterial blood gases; ECG: Electrocardiography

\section{Acknowledgements}

Not applicable.

\section{Authors' contributions}

SE and WM were responsible about the study concept and design. ME performed spirometry for all participants. Hemodynamic parameters were measured by WK and AE. SE and WM were responsible about patient selection, acquisition, analysis, and interpretation of data. Preparation of the draft was carried out by WK. The manuscript was substantially revised by SE, WM, and ME. All contributing authors have read and approved the final manuscript file.

\section{Funding}

Not applicable.
Availability of data and materials

Data used are available upon request.

\section{Ethics approval and consent to participate}

The Ethics Committee of Zagazig Faculty of Medicine approved the current study. A reference number is not applicable. An informed written consent was collected from each participant.

Consent for publication

A consent for publication was obtained from all contributors.

\section{Competing interests}

Authors declare that they have no competing interests.

\section{Author details}

${ }^{1}$ Pulmonary Medicine Department, Zagazig Faculty of Medicine, Zagazig, Egypt. ${ }^{2}$ Cardiology Department, Zagazig Faculty of Medicine, Zagazig, Egypt.

Received: 21 March 2020 Accepted: 19 June 2020

Published online: 31 July 2020

\section{References}

1. Agusti AG (2005) Systemic effects of chronic obstructive pulmonary disease. Proc Am Thorac Soc 2:367-370

2. Cinarka H, Kayhan S, Gumus A, Durakoglugil ME, Erdogan T, Ezberci I et al (2014) Arterial stiffness measured via carotid femoral pulse wave velocity is associated with disease severity in COPD. Respir care 59:274-280

3. Sin DD, Man SF (2005) Chronic obstructive pulmonary disease as a risk factor for cardiovascular morbidity and mortality. Proc Am Thorac Soc 2:8-11

4. Mills NL, Miller JJ, Anand A, Robinson SD, Frazer GA, Anderson D et al (2008) Increased arterial stiffness in patients with chronic obstructive pulmonary disease: a mechanism for increased cardiovascular risk. Thorax 63:306-311

5. McAllister DA, Maclay JD, Mills NL, Mair G, Miller J, Anderson D et al (2007) Arterial stiffness is independently associated with emphysema severity in patients with chronic obstructive pulmonary disease. Am J Respir Crit Care Med 176:1208-1214

6. Vogelmeier CF, Criner GJ, Martinez FJ, Anzueto A, Barnes PJ, Bourbeau J et al (2017) Global strategy for the Diagnosis, Management, and Prevention of Chronic Obstructive Lung Disease 2017 Report. GOLD Executive Summary. Am J Respir Crit Care Med 195:557-582

7. Launois C, Barbe C, Bertin E, Nardi J, Perotin JM, Dury S et al (2012) The modified Medical Research Council scale for the assessment of dyspnea in daily living in obesity: a pilot study. BMC Pulm Med 12:61

8. American Thoracic Society (2002) ATS statement: guidelines for the sixminute walk test. Am J Respir Crit Care Med 166:111-117

9. Celli BR, Cote CG, Marin JM, Casanova C, Montes de Oca M, Mendez RA et al (2004) The body-mass index, airflow obstruction, dyspnea, and exercise capacity index in chronic obstructive pulmonary disease. N Engl J Med 350: 1005-1012

10. Van Bortel LM, Laurent S, Boutouyrie P, Chowienczyk P, Cruickshank JK, De Backer T et al (2012) Expert consensus document on the measurement of aortic stiffness in daily practice using carotid-femoral pulse wave velocity. J Hypertens 30:445-448

11. Wassertheurer S, Kropf J, Weber T, van der Giet M, Baulmann J, Ammer M et al (2010) A new oscillometric method for pulse wave analysis: comparison with a common tonometric method. J Hum Hypertens 24:498504

12. Roeder M, Sievi NA, Kohlbrenner D, Clarenbach CF, Kohler M (2020) Arterial stiffness increases over time in relation to lung diffusion capacity: a longitudinal observation study in COPD. Int J of Chron Obstruct Pulmon Dis 15:177-187

13. Sabit R, Bolton CE, Edwards PH, Pettit RJ, Evans WD, McEniery CM et al (2007) Arterial stiffness and osteoporosis in chronic obstructive pulmonary disease. Am J Respir Crit Care Med 175:1259-1265

14. Zureik M, Benetos A, Neukirch C, Courbon D, Bean K, Thomas F et al (2001) Reduced pulmonary function is associated with central arterial stiffness in men. Am J Respir Crit Care Med 164:2181-2185

15. Mahmud A, Feely J (2003) Effect of smoking on arterial stiffness and pulse pressure amplification. Hypertension 41:183-187 
16. Rehill N, Beck CR, Yeo KR, Yeo WW (2006) The effect of chronic tobacco smoking on arterial stiffness. Br J Clin Pharmacol 61:767-773

17. Divo M, Cote C, de Torres JP, Casanova C, Marin JM, Pinto-Plata V et al (2012) Comorbidities and risk of mortality in patients with chronic obstructive pulmonary disease. Am J Respir Crit Care Med 186:155-161

18. Maclay JD, McAllister DA, Macnee W (2007) Cardiovascular risk in chronic obstructive pulmonary disease. Respirology 12:634-641

19. Zieman SJ, Melenovsky V, Kass DA (2005) Mechanisms, pathophysiology, and therapy of arterial stiffness. Arterioscler Thromb Vasc Biol 25:932-943

20. Schulz E, Arfai K, Liu X, Sayre J, Gilsanz V (2004) Aortic calcification and the risk of osteoporosis and fractures. J Clin Endocrinol Metab 89:4246-4253

21. Puhan MA, Garcia-Aymerich J, Frey M, ter Riet G, Antó JM, Agustí AG et al (2009) Expansion of the prognostic assessment of patients with chronic obstructive pulmonary disease: the updated BODE index and the ADO index. Lancet 374:704-711

22. Boutouyrie P, Tropeano Al, Asmar R, Gautier I, Benetos A, Lacolley P et al (2002) Aortic stiffness is an independent predictor of primary coronary events in hypertensive patients: a longitudinal study. Hypertension 39:10-15

23. Witteman JC, Grobbee DE, Valkenburg HA, van Hemert AM, Stijnen T, Burger $\mathrm{H}$ et al (1994) J-shaped relation between change in diastolic blood pressure and progression of aortic atherosclerosis. Lancet 343:504-507

24. Aldabayan YS, Ridsdale HA, Alrajeh AM, Aldhahir AM, Lemson A, Alqahtani JS et al (2019) Pulmonary rehabilitation, physical activity and aortic stiffness in COPD. Respir Res 20:166

\section{Publisher's Note}

Springer Nature remains neutral with regard to jurisdictional claims in published maps and institutional affiliations.

\section{Submit your manuscript to a SpringerOpen ${ }^{\circ}$ journal and benefit from:}

- Convenient online submission

- Rigorous peer review

- Open access: articles freely available online

High visibility within the field

- Retaining the copyright to your article

Submit your next manuscript at $\boldsymbol{\nabla}$ springeropen.com 